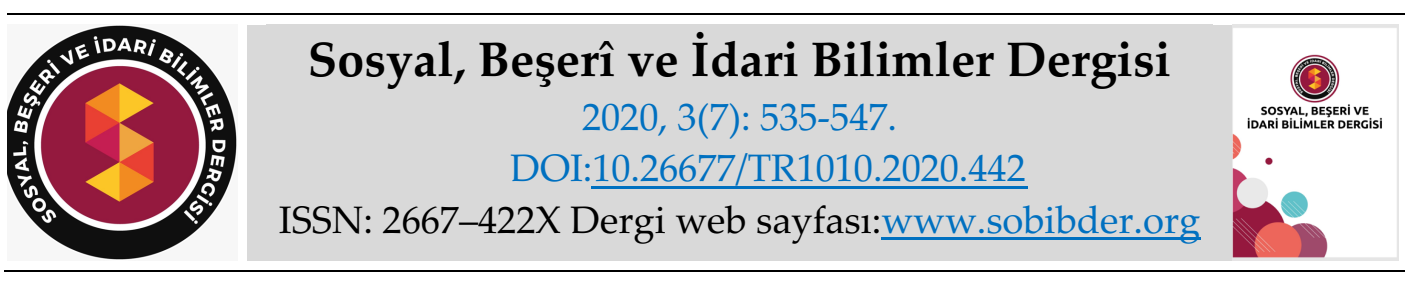

$\underline{\text { KAVRAMSAL MAKALE }}$

\title{
Sürdürülebilir Turizmin Gelişiminde Sosyal Girişimcilik: Kavramsal Bir Değerlendirme
}

Arş. Gör. Dr. Simge ŞALVARCI, Selçuk Üniversitesi, Beyşehir Ali Akkanat Turizm Fakültesi, Konya, e-posta: simge tokay@hotmail.com

ORCID: https://orcid.org/0000-0003-0703-4126

Öz

Turizm, zengin doğal ve kültürel kaynaklara sahip birçok bölge için gelir ve istihdam yaratmada temel ekonomik faaliyetlerden biridir. Ancak sahip olduğu ekonomik önem, turizmin ekolojik ve sosyo-kültürel etkilerinin göz ardı edilmesine neden olmaktadır. Toplumun artan ihtiyaçları ve bu ihtiyaçların karşılanması talepleri ile sivil toplumun önemi yeniden gözden geçirilmeye başlanmış ve bu nedenle sosyal girişimcilik gibi modeller son yıllarda artmaya başlamıştır. Sosyal girişimlerin ikincil hedefleri kâr elde etmek olup, temel hedefleri sosyal fayda yaratmaktır. Bugün, farklı endüstriler arasındaki sınırlar giderek ortadan kalkmakta ve bu endüstrilerin yaratmaya çalıştı̆̆ sosyal faydalar farklı yönlerde şekillenmektedir. Turizm endüstrisi de bu endüstrilerden biridir. Endüstride, artık bireylerin ve kurumların sosyal yardım yaratma çabalarının ikincil bir görevden ziyade ana misyonlarından biri haline geldiği görülmektedir. Bu nedenle, sosyal fayda yaratan en önemli iş modellerinden biri olan sosyal girişimciliğin önemi gün geçtikçe artmaktadır. Bu doğrultuda çalışmanın amacı; sürdürülebilir turizmin gelişimi açısından sosyal girişimciliğin önemi ve rolü hakkında bilgi vermektir. Bu bilgiler doğrultusunda turizm endüstrisinde uygulanmakta olan örnek olaylara değinilmektedir. Ayrıca, turizm alanlarında sürdürülebilir girişimciliğin gelişmesine yönelik olarak çeşitli önerilerde bulunulmaktadir.

Anahtar Kelimeler: Sürdürülebilir Turizm, Sosyal Girişimcilik, Sürdürülebilir Kalkınma, Turizm.

Makale Gönderme Tarihi: 28.04.2020

Makale Kabul Tarihi: 03.07.2020

\section{Önerilen Atıf:}

Şalvarcı, S. (2020). Sürdürülebilir Turizmin Gelişiminde Sosyal Girişimcilik: Kavramsal Bir Değerlendirme, Sosyal, Beşeri ve İdari Bilimler Dergisi, 3(7): 535-547.

(c) 2020 Sosyal, Beşerî ve İdari Bilimler Dergisi. 


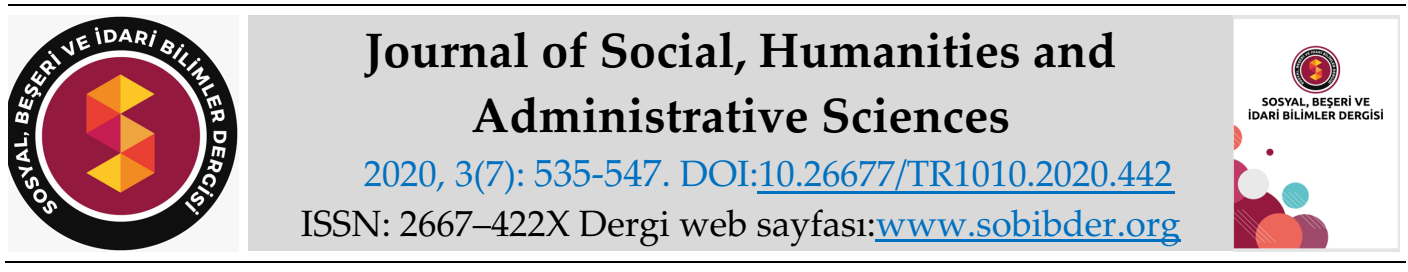

\title{
CONCEPTUAL PAPER
}

\section{Social Entrepreneurship in The Development of Sustainable Tourism: A Conceptual Evaluation}

Dr. Simge ŞALVARCI, Selçuk University, Beyşehir Ali Akkanat Faculty of Tourism, e-mail: simge tokay@hotmail.com ORCID: https://orcid.org/0000-0003-0703-4126

\begin{abstract}
Tourism is the basic economic activity in generating income and employment for many regions with rich natural and cultural resources. However, this economic importance causes the ecological and socio-cultural effects of tourism to be ignored. With the increasing needs of the society and the demands to meet these needs, the importance of civil society has begun to be revised and for this reason, models such as social entrepreneurship have started to increase in recent years. The secondary goals of social enterprises are to generate profit and their main goals are to create social benefits. Today, the borders between different sectors are gradually disappearing and the social benefits that these sectors try to create are shaped in different directions. Tourism sector is one of these sectors. In the sector, it is seen that the efforts of individuals and institutions to create social assistance have become one of their main missions rather than a secondary task. For this reason, the importance of social entrepreneurship, which is one of the most important business models creating social benefits, is increasing day by day. Accordingly, the purpose of this study is; to give information about the importance and role of social entrepreneurship in terms of sustainable tourism development. In line with this information, case studies in the tourism industry are mentioned. In addition, various suggestions are made for the development of sustainable entrepreneurship in tourism.
\end{abstract}

Keywords: Sustainable Tourism, Social Entrepreneurship, Sustainable Development, Tourism.

Received: 28.04 .2020

Accepted: 03.07.2020

\section{Suggested Citation:}

Şalvarc1, S. (2020). Social Entrepreneurship in The Development of Sustainable Tourism: A Conceptual Evaluation, Journal of Social, Humanities and Administrative Sciences, 3(7): 535-547.

(c) 2020 Sosyal, Beşerî ve İdari Bilimler Dergisi. 


\section{Gíriş}

Sürdürülebilir kalkınmanın popüler hale gelmesinin ardından, 1980'li yılların sonlarında çevre yönetimi kavramı, turizm araştırma literatürünün önemli bir bölümünde sürdürülebilir turizm gelişiminin ilke ve uygulamalarına odaklanmıştır. "Sürdürülebilir turizm" terimi, bir destinasyonun çevresel kaynak tabanı (doğal, inşa edilmiş ve kültürel özellikler dâhil) korunacak şekilde turizm gelişimi için bir yol çizen bir dizi ilke, politika ve yönetim süreçlerini temsil etmekte ve kapsamaktadır (Lane, 1994).

Birleşmiş Milletler Çevre Programı ve Birleşmiş Milletler Dünya Turizm Örgütü (2005), sürdürülebilir turizmi "mevcut ve gelecekteki ekonomik, sosyal ve çevresel etkilerini tam olarak dikkate alan ve ziyaretçilerin, endüstrinin, çevrenin ve ev sahibi toplulukların ihtiyaçlarını ele alan turizm" olarak tanımlamaktadır (De Lange ve Dodds, 2017). Sürdürülebilir turizm gelişimi ise, "kültürel miras, temel ekolojik süreçler, biyolojik çeşitlilik ve yaşam destek sistemleri korunarak ekonomik, sosyal ve estetik ihtiyaçların karşılanabileceği şekilde tüm kaynakların yönetimi" olarak düşünülmektedir (Dünya Turizm Örgütü, 2000). Seyahat ve Turizm Gündemi 21, turizmin kırsal alanlara sağlayabileceği faydaları vurgulamaktadır. Bu durum, uzun vadeli bir perspektif ve turizm ile çevrenin birbiriyle olan ilişkilerinin dikkatle ele alınmasını gerektirmektedir (Flavin, French ve Gardner, 2002).

Turizm endüstrisindeki sürdürülebilirliğin temel unsurları, sürdürülebilir kalkınmanın üç temel direğini yansıtması gereken bir turizm biçimi olması bakımından evrenseldir. Bunlar, topluma fayda sağlamak, çevreyi koruyarak saygı göstermek ve gelecek nesiller dikkate alındığında uzun vadede ekonomik olarak uygulanabilir olmaktır (Butler, 1999; McCool ve Lime, 2001; Bramwell ve Lane, 2002; Kensbock ve Jennings, 2011).

Turizmde gözlenen eğilimler, küçük ölçekli, doğa ile ilgili olduğunu ve kırsal turizme olan talebin arttığını göstermektedir. Turizm, hızlı uluslararası pazar büyümesi nedeniyle girişimci endüstrinin büyük oranda katılımının gerektiği ekonomik endüstrilerden biridir (Dünya Turizm Örgütü, 2000). Kırsal kalkınmaya ilişkin girişimci bir yönelim, yerel girişimcilerin teşvik edilmesine, böylece istihdam yaratmaya ve bir bölgeye ve topluma ekonomik değer katmaya ve aynı zamanda toplum içinde kıt kaynakları sürdürülebilir kılmaya dayandırılmaktadır (Petrin ve Gannon, 1997). Ayrıca, ihtiyaç duyulan durum, sürdürülebilir kalkınma taleplerini bir çıkış noktası olarak ele alan, sorumlu girişimciliği geliştirmeyi sağlayan bir ortamdır (Lordkipanidze, Brezet ve Backman, 2005: 787-788).

$\mathrm{Bu}$ çalışma, turizm endüstrisinde sosyal girişimcilik yoluyla yenilikçiliğin teşvik edilmesinin endüstride yer alan sorunların ele alınmasına yardımcı olacağını ileri sürmektedir. Bu nedenle, çalışma sosyal girişimcilik ve sürdürülebilir turizm arasındaki ilişkiyi açıklamaktadır. Böylece her iki kavramın endüstride sürdürülebilirliğin sağlanması için nasıl hizmet edebileceğine dair önerilerde bulunulmaktadır. İlk olarak, hem sürdürülebilir turizm hem de sosyal girişimcilik terimlerinin yanı sıra konunun önemi açıklanmaktadır. Ayrıca, çalışmada turizm endüstrisinde sosyal girişimcilik ve sürdürülebilirliğe ilişkin örnekler verilmektedir. Araştırmanın alt amacı ise, sosyal girişimciliğin sürdürülebilir turizmde yansımasını açılamanın yanı sıra turizm literatürü kapsamında değerlendirmektir.

\section{Sürdürülebilir Turizm Gelişimi}

'Sürdürülebilir turizm' terimi, sürdürülebilirlik terimi ile kalkınma ve turizm endüstrisinin sürdürülebilir olma ihtiyacından (Jackson ve Morpeth, 2000) ortaya çıkmıştır. Terim, literatürde Rio Dünya Zirvesi sonrası sürdürülebilir kalkınma çerçevesinde ele alınmış olsa da Weaver ve Lawton (1999), turizmin sürdürülebilirliği konusundaki dolaylı tartışmanın 1950'lerden beri var 
olduğunu ve sürdürülebilirliğin ortaya çımasının baskın bir paradigma haline geldiği 1990'lara kadar çeşitli aşamalardan geçtiğini öne sürmektedir. Sürdürülebilir kalkınma terimi hakkında tartışmalar olduğu gibi, sürdürülebilir turizm kavramının çeşitli algısı, sürdürülebilirlik kavramını turizme uyarlamada karmaşıklıklara yol açmıştır (McDonald, 2006: 45).

Buckley (2002), sürdürülebilir turizmi “çevresel etkileri azaltmak için pratik ve proaktif tasarım, mühendislik ve yönetim ile her ölçekte turizmin ele alınması" olarak tanımlamaktadır. Scharpf (1998) ise, sürdürülebilir turizmi; doğal, kültürel ve sosyal kaynakları uzun vadede daha iyi hale getiren ve koruyan, olumlu ve 1 lımlı bir tarzda ekonomik gelişmeyi destekleyen bir turizm olarak açıklamaktadır (akt. Duran, 2009). Lane (1991:2) sürdürülebilir turizmden, yerel ekonomiye hâkim olmadan veya doğal çevreyi kötüye kullanmadan tatmin edici işler sergilemek olarak bahsetmiştir.

Sürdürülebilir turizm gelişimi terimi genellikle turizm içindeki kalkınmaya daha bütünsel bir yaklaşım kazandırmak için kullanılmaktadır. Sürdürülebilir turizm gelişimi, sürdürülebilir turizm ile yakından ilişkilidir, ancak daha spesifik olarak turizmdeki gelişmenin sürdürülebilir olmasını sağlama ihtiyacını ele almaktadır. Sürdürülebilir turizm hem turizmin ekonomiye ve topluma katkısının sürdürülebilir büyümesini hem de kaynakların ve çevrenin sürdürülebilir kullanımını gerektirir. Her iki durumda da, turizm talebinin iyi bir şekilde anlaşılmadan ve doğru yönetimi sağlanmadan gerçekleştirilmesi mümkün olmamaktadır. Ancak, sınırlı sayıda araştırmacı (örn. Middleton ve Hawkins, 1998; Butler, 1999) ve genellikle bir etki kontrol önlemi olarak kullanılan yerinde ziyaretçi yönetimi haricinde, sürdürülebilir turizm tartışmasında talep sorunları genellikle göz ardı edilmiştir (Liu, 2003).

Sürdürülebilir kalkınmanın içeriğinde yer alan başlıca hususlar (Hunter, 1997: 852):

- Ekonomik büyümenin insan refahını desteklemedeki rolü,

- Toplum nüfusunun artmasının etkisi ve önemi,

- Gelişim için çevresel sınırların etkili varlığı,

- Doğal kaynakların (sermayenin) ekonomik büyüme ve teknik yenilik yoluyla yaratılan insan yapımı sermaye ile yer değiştirebilirliği,

- Doğal kaynak tabanının çeşitli bileşenlerinin kritikliğinin ve dolayısıyla ikâme potansiyelinin diferansiyel yorumu,

- Teknolojilerin (çevresel etki değerlendirmesi ve çevre denetimi gibi yönetim yöntemleri dâhil) ekonomik büyümeyi ve istenmeyen çevresel yan etkileri birbirinden ayırma becerisi,

- Doğal dünyaya atfedilen değerin anlamı ve diğer canlıların duygusal veya başka türlü hakları,

- Sistemler (ekosistemler) perspektifinin ne ölçüde benimsenmesi gerektiği şeklinde siralanmaktadir.

Sürdürülebilir turizm, her evresinde toplumsal sorumluluk, ekonomik verimlilik ve doğaya yönelik duyarlılığı kapsamaktadır. Bu noktada, doğanın korunmasının yanı sıra sosyal ve kültürel değerlerin de korunması ve sürdürülebilir kılınması oldukça önemlidir (Duran, 2009: 3). Bu bağlamda, turizm endüstrisinin mevcut durumunu koruyarak sürdürülebilirliğini sağlaması turizme kaynak oluşturan bölgesel ve yerel alanlara özgü doğal ve kültürel değerlerin muhafaza edilerek kullanılmasıyla mümkün olabilir (Beyhan ve Ünügür, 2005: 80).

\section{Turizm Endüstrisinde Sosyal Girişimcilik}

Sosyal girişimciliğin, ortaya çıkışından bu yana, çok sayıda kapsamlı ve tamamlayıcı tanım literatürde yer almıştır. Sosyal girişimcilik, en basit haliyle merkezi sosyal amaçlı bir ticari faaliyet 
olarak tanımlanmaktadır. Austin, Stevenson ve Wei-Skillern (2006) sosyal girişimciliği, "iş dünyası veya hükümet endüstrileri içinde veya arasında meydana gelebilecek yenilikçi, sosyal değer yaratan faaliyetler" olarak tanımlamaktadır. Dees'e (2001) göre, "sosyal girişimcilik, sosyal bir misyonu iş benzeri disiplin, yenilikçilik ve kararlılıkla birleştiren girişimci faaliyetleri kapsamaktadır".

Sosyal işletmelerin amacı, öncelikle kişisel veya hissedar servetini artırmayı amaçlayan geleneksel ticari işletmelerin aksine (Abu-Saifan, 2012), süreçlerine ve daha geniş topluluklara dâhil olan bireyler arasında sosyal ve ekonomik zenginliği daha eşit bir şekilde dağıtmaktır (Shaw ve Carter, 2007; Zahra, Gedajlovic, Neubaum ve Shulman, 2009). Bu durum göz önüne alındığında, sosyal girişimcilik aynı zamanda bir "sosyal yenilik" ya da insanların yaşam kalitesini olumlu yönde etkileme potansiyeline sahip yaratıcı fikirlerin benimsenmesi şeklinde öne sürülmektedir (Pol ve Ville, 2009). Başka bir deyişle, sosyal girişimcilik, toplumun uyum kapasitesini göz önünde bulundurarak, toplumsal sorunlarla ilgilenirken yüksek oranda kapsayıcılık ve yaratıcılık ile ilişkilidir (Zeyen vd., 2013).

Sosyal girişimcilik faaliyetini anlamak için, sosyal girişimciliği, girişimcilikle karşılaştırmak ve aynı zamanda ortak noktaları tanımak önemlidir. Sosyal girişimcilik, farklılıkların yenilikçi ve / veya girişimin amaç ve genel amaçlarında bulunan girişimcilikten alınmış bir kavramdır (Lepoutre, Justo, Terjesen ve Bosma, 2013). Sosyal girişimciliğin girişim olarak değerlendirilmesi için, ilgili faaliyet sosyal konuları daha geniş bir bağlamda ele almalı ve çözmeye çalışmalı ve/veya sürdürülebilir bir çözüm yaratmak için sosyal amaçlı daha fazla etkinliği teşvik etmelidir (Mair ve Marti, 2006). Prieto, Phipps ve Friedrich (2012: 9) New York Üniversitesi'nin sosyal girişimcilerin niyetleri hakkındaki görüşlerini ele almaktadır. New York Üniversitesi üç çeşit bireyi ve niyetlerini siralamaktadır (De Lange ve Dodds, 2017: 1980):

(1) Belirli bir sosyal soruna karşı sürdürülebilir ve ölçeklenebilir bir şekilde çözüm bulmak için yenilikçi bir fikir sahibi olan veya geliştirmeyi planlayanlar;

(2) Sosyal girişimci faaliyetlerin kök salması için gerekli altyapıyı oluşturacak ve/ veya inşa edecek olanlar;

(3) Belirli sosyal sorunlara ulusal ve/veya küresel ölçekte eyleme yönelik farkındalık getirecek olanlar.

Grassl (2012: 51) ise, bir sosyal girişim için aşağıda yer alan koşulları savunmaktadır:

- Sosyal bir misyon tarafından yönlendirilmelidir (yani hissedarlara kâr dağıtmaktan kaçınmak),

- Toplum için olumlu dışsallıklar yaratmalıdır,

- Girişimci fonksiyonun merkezi özelliğini tanımalıdır,

○ Etkin planlama ve yönetim yoluyla pazarlarda rekabet gücü sağlamalıdır.

Sheldon, Pollock ve Daniele (2017), turizmde sosyal girişimciliği; “sürdürülebilir sosyal dönüşüm için gerekli olan destinasyonun içinden veya dışından fikirleri, kapasiteleri, kaynakları ve sosyal anlaşmaları harekete geçirerek destinasyonlarda acil sosyal, çevresel ve ekonomik sorunlara yenilikçi çözümler yaratmak için turizmi kullanan bir süreç" olarak tanımlamaktadır.

Dünyada turizm alanında faaliyet gösteren çeşitli sosyal girişim örnekleri bulunmaktadır. Bunlar arasında; Amerika'da Grand Canyon Skywalk, Avustralya'da Kuku Yalanji Dreamtime, Kanada'da The Cree Village Ecolodge (Rebutin, 2009; Günlü, 2015), Tayvan'in Hengshan bölgesinde gerçekleştirilen projeler (Peng ve Lin, 2016) ve Afrika'da Growing the Future Projesi (Laeis ve Lemke, 2016) sayılabilir. Türkiye'de turizm alanında faaliyet gösteren sosyal girişim sayısı oldukça azdır (Çiftçi ve Zencir, 2019). Buna örnek olarak ise, bir gençlik kuruluşu olarak, öğrenci ve gençlerin bireysel ve sosyo-kültürel gelişimlerine katkı sağlayacak her türlü etkinliğe katılabilmeleri için imkân sunan, ticari ve hukuki problemlerin çözümüne destek gibi konularda 
sosyal fayda yaratılmasını hedefleyen sosyal bir girişim olan GENÇTUR (Kulakoğlu Dilek ve Dilek, 2018) verilebilir.

İdeal olarak, turizm endüstrisindeki girişimcilik yoluyla, yerel girişimcilerin teşvik edilmesi, böylece ekonomik değerlere yardımcı olmak ve kaynakları yerel toplum içinde tutmak (Petrin ve Gannon, 1997 akt. Lordkipanidze vd., 2005: 787) sağlanabilmektedir.

\section{Turizmde Sosyal Girişimcilik ve Sürdürülebilir Gelişim İlişkisi}

Sürdürülebilir kalkınmanın orijinal kavramları 1968 yılında gerçekleştirilen Paris Biyosfer Konferansı, Washington'daki Uluslararası Kalkınma Ekolojik Boyutları Konferansı ve 1972'de Birleşmiş Milletler İnsan Çevresi Konferansi'na kadar uzanmaktadır. Ancak, 1987 yılına kadar Dünya Çevre ve Kalkınma Komisyonu tarafından sürdürülebilirlik ve sürdürülebilir kalkınma kavramı yaygınlaştırılmıştır (Tosun, 1998: 596).

Rio Dünya Zirvesi'nden sonra sürdürülebilirlik ilkelerini faaliyete geçirme girişiminde bulunan Jacobs (1991), 'sürdürülebilirlik' terimi ve bunun nasıl uygulanabileceği ile ilgili üç önemli nokta önermiştir. İlk nokta, kurumların çevresel hususları mantıklı ve tutarlı bir şekilde politika ve uygulamaya dâhil etmesi gerektiğini belirtmektedir. İkinci olarak, doğal kaynak stokunun tükenmesi adil değildir ve gezegenin doğal sermayesi açısından kuşaklararası eşitlik olmalıdır. Üçüncüsü, sürdürülebilir kalkınma ekonomik büyüme ile eşanlamlı olarak görülmemelidir. Toplumsal refahın, kültürel değerlerin ve çevrenin içsel değerinin, gelişimin kapsamlı bir incelemesi Jacobs (1991) tarafından gerekli görülmüştür. Bu üç husus, gelecek nesiller için çevreyi korurken Dünya Çevre ve Kalkınma Komisyonu'nun ekonomik büyüme fikrini de destekler niteliktedir (McDonald, 2006).

Sosyal girişimcilik organizasyonunu yöneten iki güç bulunmaktadır. Birincisi, hedeflenen toplumsal değişimin doğası yenilikçi, girişimci bir çözümden, ikincisi ise kurumun ve hizmetlerinin sürdürülebilirliğinden yararlanır. Kuruluşun zaman içinde kendini devam ettirme ve tüm paydaşlar için uzun vadeli kalıcı değer yaratma ve hedef sosyal etkisini derinleştirme kapasitesini ifade eder (Alter, 2006; von der Weppen ve Cochrane, 2012; Volkmann vd., 2012; Koenig, 2013).

Turizmde sürdürülebilirlik ve sürdürülebilir kalkınma için birçok tanım yer almaktadır (Butler, 1999; Page ve Dowling, 2002). Dünya Turizm Örgütü (2001) sürdürülebilir kalkınmaya ilişkin: "sürdürülebilir turizm gelişimi, gelecek için fırsatları korurken ve geliştirirken mevcut turistlerin ve ev sahibi bölgelerin ihtiyaçlarını karşılamaktadır" tanımını tercih etmektedir. Tüm kaynakların kültürel bütünlügü̈, temel ekolojik süreçleri, biyolojik çeşitliliği ve yaşam destek sistemlerini korurken ekonomik, sosyal ve estetik ihtiyaçların karşılanabileceği şekilde yönetilmesi söz konusudur (Liu, 2003). 


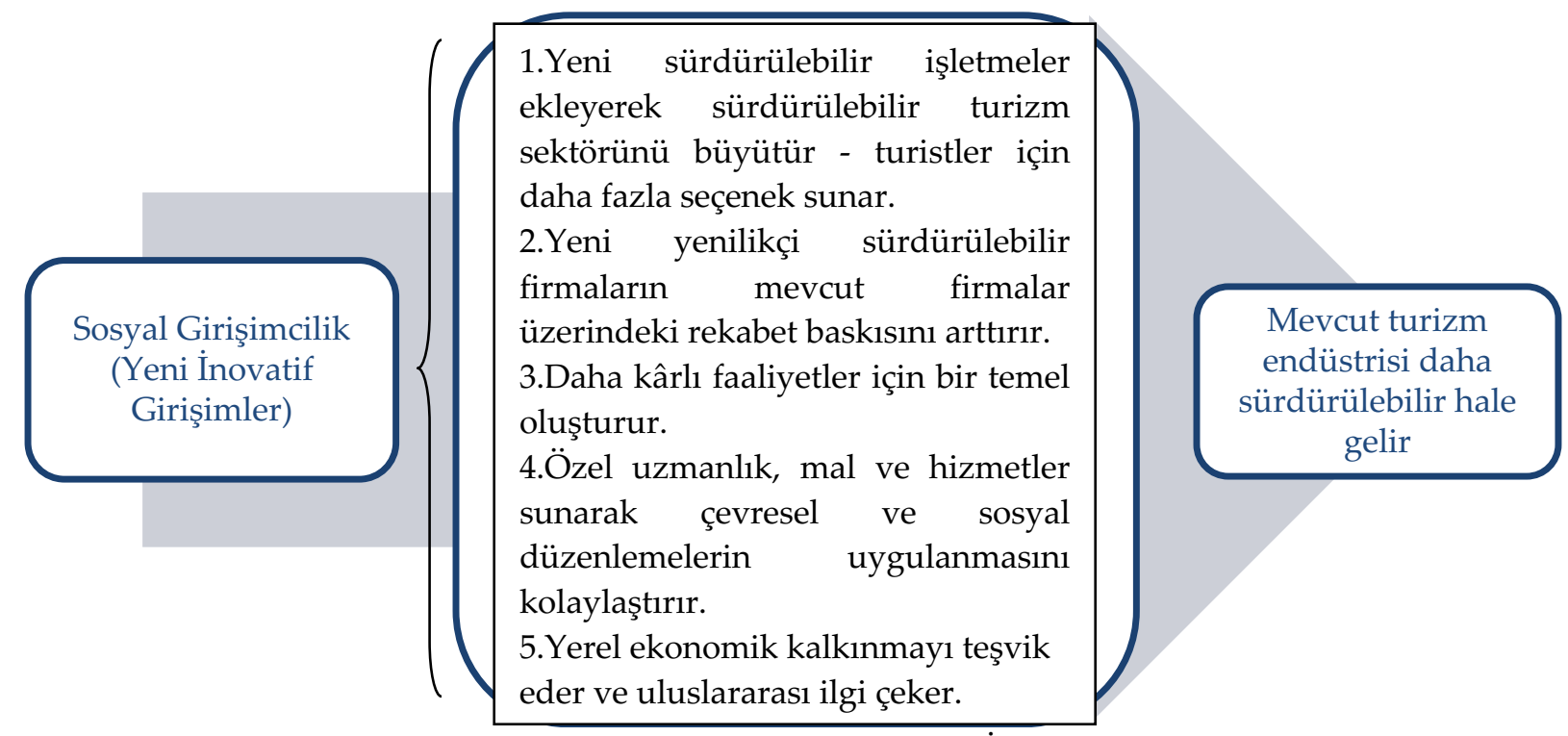

Şekil 1. Sosyal Girişimcilik ve Sürdürülebilir Turizm Arasındaki İlişki Kaynak: De Lange ve Dodds, 2017: 1982.

Bireysel girişimciliğin aksine, sosyal girişimcilik, gelişmeleri toplumsal bağlamda yaygın hale getirmek için yenilikçi düşünce ve yaratıcı kavramsallaştırmayı içerir. Sosyal girişimciliğin bütünsel süreci, daha fazla bireyin sinerjisini bütünleştirir, toplumsal yeniliklerin elverişli fırsatlar yaratmasını ve aynı zamanda günümüzde risk ve belirsizliklerle başa çıkmak için küreselleşmiş dünyada bir katalizör görevi görmesini destekler (Tetzschner ve Herlau, 2003). Bu bakış açısıyla, sosyal girişimcilik, kaynakların daha etkili bir şekilde kullanılmasına yönelik uygun bir yöntem haline gelebilir. Buna bağlı olarak ise, turizmin yerel topluluklara yönelik faydalarını artırarak sürdürülebilir turizm gelişimine yol açabilir.

Sosyal girişimcilik ve sürdürülebilir kalkınma bağlantısı ile ilgili olarak Dees (1998: 4), sosyal girişimciliğin sürdürülebilir kalkınma üzerinde etkili olabilmesi ve katkıda bulunabilmesi için gerekli olan bir dizi kimlik bilgisine atıfta bulunduğunu iddia etmektedir. Yazara göre, bu unsurlar (Boukas ve Chourides, 2016):

1. Toplumsal değer yaratma ve sürdürme misyonunu benimseme,

2. Bu misyona hizmet etmek için yeni fırsatları tanıma ve sürekli olarak takip etme,

3. Sürekli yenilik, adaptasyon ve öğrenme sürecine katılma,

4. Mevcut kaynaklarla sinırlı kalmama,

5. Sunulan seçenekler ve oluşturulan sonuçlar karşısında daha fazla sorumlu olmadır.

Turizm endüstrisi daha sürdürülebilir hale gelmek için gelişebilir veya sürdürülebilir turizm, endüstride özel bir niş alan olarak kalabilir (Lansing ve De Vries, 2007; Ruhanen, 2013). Her iki durum da sürdürülebilir turizm olarak kabul edilmektedir. Bu iki durumun tam olarak ayrıştırılması zor olabilir, ancak birincisi, sürdürülebilir faaliyetlerin iş modellerinin temelini oluşturduğu mevcut işletmeler için sürdürülebilir iyileştirmeler benimsemek olarak nitelendirilebilir. Buna karşılık, niş, endüstride yeni girişimler yaratan yepyeni bir yenilikçi sürdürülebilir fırsat olma özelliğini temsil eder. Sosyal girişimcilik, daha büyük işletmeler tarafından ortaya atılan sosyal girişimcilik faaliyetlerine verilen addır. Daha büyük bir işletme sosyal yardım türü projeler başlatabilir ve/veya bir işletmenin toplum üzerindeki genel etkisini azaltmayı hedefleyebilir. Buna karşılık, yeni başlangıçlar sosyal girişimciliği temsil etmektedir. Sosyal girişimcilik, girişimciliğin kritik kalitesini, yani kâr amaçlı veya kâr amacı gütmeyen inovasyonlar üretmeyi sürdürmektedir. Bununla birlikte, inovasyonlar, işletmenin sürekliliğini sağlamak için ekonomik sürdürülebilirliğin bir gereklilik olduğu sosyal ve / veya çevresel 
iyileştirmelerle ilgilidir (Lepoutre vd., 2013). Bu yenilikler, ister yeni sürdürülebilir başlangıçlar üreten artışlar, ister ileri adımlar olsun her iki sürdürülebilir turizm türüyle de ilişkili olabilir (De Lange ve Dodds, 2017).

\section{Sürdürülebilir Turizme Yönelik Sosyal Girişimcilik Örnekleri}

Gervide Gard, bir ada bölgesinde olma özelliğinden yararlanarak İsveç'in Gotland adasının merkezinde yer alan, çiftlik turizminde faaliyet gösteren bir aile işletmesidir. Çiftliğin sahibi süt ineklerine sahipti, ancak 1988 yılında sağlık durumunun kötüleşmesi çiftçiyi süt üretiminden vazgeçmeye ve çiftliği kullanmanın alternatif yollarını değerlendirmeye zorlamış; böylece odak noktasını kırsal turizme taşımıştır. Bugün çiftlikte birçok aktivite bulunmaktadır. Atlar ve binicilik de dâhil olmak üzere çeşitli hayvanlar yer almakta olup at biniciliği ana faaliyetlerden biri konumundadır. Ayrıca havaya atış, Gotlandic pentatlon çeşidi, yerel 'Rus' atlarla iki tekerlekli at arabası sürüşü, röle sürüşü, balta atma ve traktör sürüşü de mevcuttur. Çiftlik ayrıca Gotland'daki yerel at ırkı olan Rus atlarına ilişkin tek müze olup bugün dünyanın en uzun atına ev sahipliği yapmaktadır. İşletmenin salon tarzında bir restoranı vardır. Yemek ve konaklama imkânı sunulmaktadır. Sahipleri, bazı komşu evleri ve eski bir okulu satın almış ve onları diğer bazı binalarla birlikte turizm konaklama birimlerine dönüştürmüştür. Tarım arazisi bir Demir Çağı köyünün kalıntılarını içermektedir ve projelerden biri de, tarihi yemeklere sahip ziyafetlerin yer aldığı bir Demir Çağı çiftlik evinin taklidini inşa etmek olmuştur. Gervide Gard, Gotland'ın eşsiz kültüründen yararlanmıştır. Tek pazarlama unsuru ise internette bir web sayfası olmuştur. İsii kurmak ve geliştirmek için gereken sermaye, ailenin tasarruflarından ve işletmenin kârlarından elde edilmiştir. Gervide Gard gibi bir işi yürütmek, bir yaşam biçimi haline gelmiştir. Aile, ziyaretçilere verilen deneyimin bir parçasını oluşturmaktadır. Çiftliğin gelişimi; kendi gelişimleri ve kişilikleriyle yakından bağlantılıdır. İşletmeyi geliştirmişler ve büyüklüğünü daha da arttırmak için çaba sarf etmemekteler. Ailenin verdiği mesaj ise hem doğada hem de kendi içinde mevcut kaynakları korumak ve kişinin vizyonunu gerçekleştirmek için sürdürülebilir kalmanın önemine vurgu yapmaktadır (Lordkipanidze vd., 2005).

Kanada'daki G Adventures'ın (bir tur operatörü) kâr amacı gütmeyen kuruluşu olan Planeterra Vakfı, yerel ve yurtdışında ana akım tur operatörlerinin tekliflerinin bir parçası haline gelen toplum girişimlerini teşvik etmek için birçok girişimde bulunmuştur. Peru, Huchuy Qosco köyünde, Planeterra, \% 100 oranında yerel toplum tarafından sahip olunan ve işletilen bir halk restoranı açılmasına katkıda bulunmuştur. Operasyonun ilk dokuz ayında, Parwa Restoran 16.000 kişiye hizmet vermiş ve 160.000 ABD doları gelir elde etmiştir. Kârları, yönetim için iki katlı bir bina, çalışanlar tarafından kullanılmak üzere odalar ve banyolar, bahçeler, yemek alanı için cam duvarlar inşa edilerek ve tabak ve çatal bıçak takımı gibi daha fazla servis malzemesi satın alarak işe geri yatırılmıştır. Ayrıca kendi toplum projelerinden üçünü geliştirebilmişlerdir: bir bilgisayar laboratuvarı ve kütüphanesi, köyün yaşlıları için bir evde bakım programı ve Huchuy Qosco'nun tüm çocukları için bir burs programı (Planeterra, 2015; akt. De Lange ve Dodds, 2017).

Arap Denizi'nin Malabar Sahili'nde bulunan Güney Hindistan Kerala Eyaleti 38,864 kilometrekarelik bir coğrafi alanı kaplamaktadır ve yaklaşık 31 milyonluk bir nüfusa sahiptir. 'Kerala Geliştirme Modeli' ile tanınan, tamamen okuryazar bir nüfusa ve gelişmiş batı toplumlarıyla karşılaştırılabilecek fiziksel bir yaşam kalitesi indeksi derecesine sahiptir. Kerala'da bir turizm ürünü olarak yüzen evlerin geliştirilmesi, turizm gelişimine sürdürülebilirlik odaklı bir yaklaşımın bir örneğidir. Bunlar, etnik malzemeler ve bina tasarımı kullanarak büyük geleneksel ahşap yük gemilerine inşa edilen küçük evler ve devlet tarafından geliştirilen turizmin önemli bir bileşenini temsil etmektedirler. Konsept, Kerala'nın temel doğal 
varlığı etrafında şekillenmiştir. Ayrıca, dünyanın en güzel ve en geniş arka su yolu sistemini oluşturmaktadır. Doğal ve kültürel bir cazibe olarak, suyolları Kerala turizminin benzersiz pazarlama aracı olarak tanımlanmıştır (Kerala Turizmi, 2000). Geleneksel olarak Kerala'nın büyük ulaşım altyapısını ve yerel olarak "Kettuvallams " olarak bilinen büyük mekanize olmayan ahşap tekneleri, tek yük taşımacılığı aracı olarak oluşturulmuştur. Tekne evi turizmi bir çeşit yenilikçi yerel girişimciliği ve yerli kaynakların kullanımı yoluyla sürdürülebilir odaklı bir yaklaşımı temsil etmektedir (Kokkranikal ve Morrison, 2002: 11).

\section{SONUÇ}

$\mathrm{Bu}$ çalışmanın amacı, turizm endüstrisinde sosyal girişimcilik faaliyetlerinin sürdürülebilir kalkınma için daha bütüncül bir strateji olarak kavramsallaştırılmasıdır. Turizm faaliyetleri aracıllğıyla sosyal girişimcilik, endüstrinin ev sahibi toplumlar için üretebileceği faydaları en üst düzeye çıkarırken olumsuz sonuçları en aza indirmekte ve toplumsal sorunları hafifletmek için uygulanabilir bir araç olarak hareket edebilen pazar tabanlı bir strateji oluşturmaktadır. Yenilikçi ve sürdürülebilir turizm endüstrisi uygulamalarının sürekli araştırıldığı ve geliştirildiği bir dönemde sosyal girişimcilik, geleneksel turizm girişimciliğine bir alternatif sunmaktadır.

Sosyal girişimciliğin turizm için önemi, kâr yaratırken toplumsal değer yaratma, toplumun aktif katılımını teşvik eden sosyal yenilik faaliyetlerini uygulama ve sürdürülebilir kalkınma sonuçlarını teşvik etme potansiyelinden kaynaklanmaktadır. Bu önermeler daha kapsayıcı ve sürdürülebilir bir turizm endüstrisi yaratmayı ifade etmektedir. Bununla birlikte, turizm sisteminin karmaşıklı̆̆ birçok endüstri ve bunların dinamik etkileşimleri tarafından desteklenmektedir. Bu çerçevede, turizm sosyal girişimcilerini hem sosyal girişimcilik hem de turizm bağlamında olduğu fikrine yöneltmektedir. Ayrıca sosyal girişimciler, öncelikle sosyal görevlerini uygulamadan önce ve uygulama aşamasında ev sahibi toplumları (örn. bölge sakinleri, hükümet ve diğer kamu ya da özel kurumlar) dâhil ederek, işbirliği yaparak ve onlardan karşılıklı öğrenme yoluyla durumu iyi analiz etmeleri oldukça önemlidir. Toplumsal farkındalığ beşeri sermayelerini de (örn. turizm bilgi ve becerileri) yetiştirme ihtiyacını ortaya çıkarabilmektedir. Bunların dışında, değer yaratma ve girişimcilik faaliyetlerinin sürdürülmesi, sosyal girişimciliğin sürdürülebilir toplum gelişimine ulaşmasında hayati önem taşımaktadır.

Bu çalışma çeşitli teorik katkılarda bulunmakta olup sosyal girişimcilik ve sürdürülebilir turizm ile ilgili literatürü birbirine bağlamaktadır. Böylece aralarındaki kavramsal bağı genel anlamda ve daha spesifik bir şekilde açıklamaktadır. Aralarındaki genel bağlantı, yenilik ve sürdürülebilir turizmin gelişiminden oluşmaktadır. İlgili mal ve hizmetleri sunarak sosyal ve çevresel konuların çözümüne odaklanan girişimcilik, daha büyük bir endüstrinin geniş anlamda sürdürülebilir olmasını sağlayabilir. Bu sayede, sürdürülebilir turizm bir niş alan olmaktan daha öteye gidebilir.

Sosyal girişimcilik endüstrileri sürdürülebilir kılmaktadır. Turizm endüstrisi için düşünüldügünde, sosyal girişimcilik sürdürülebilir turizm endüstrisini büyüterek ziyaretçiler için daha fazla seçenek yaratır; endüstrinin bir bütün olarak giderek daha sürdürülebilir olması için yeni yenilikçi sürdürülebilir firmaların mevcut firmalar üzerindeki rekabet baskısını arttırmaktadır. Bununla birlikte, sosyal girişimcilik, daha kârlı diğer faaliyetler için bir temel oluşturur ve böylece sürdürülebilir ekonomik kalkınmayı teşvik eder; çevresel ve sosyal düzenlemelerin uygulanmasını kolaylaştırır ve yerel ekonomik kalkınmayı teşvik ederek uluslararası düzeyde ilgi çeker. Bu nedenle, çalışmada genel olarak, sosyal bir girişimciliğin sürdürülebilir bir turizm endüstrisi oluşturmak için kritik rolünü ortaya koyan bir gerekçe sunmaktadir. 
Gelecekteki araştırmalar, bu çalışmayı sürdürülebilir bir endüstrinin diğer ülke bağlamlarında nasıl yürürlüğe girebileceğini araştırmak için bir temel olarak kullanabilir. Araştırmacılar ayrıca, sosyal girişimciliğin toplum gelişiminde uygulanması, ev sahibi toplumlar için sosyal girişimciliğin sonuçlarının gözlemlenmesi ve değerlendirilmesi, sosyal girişimciliğin sürdürülebilir turizm üzerinde etkisinin bulunup bulunmadığını araştırmak için bu kavramsal çerçeveyi işlevsel hale getirebilirler.

\section{KAYNAKÇA}

Abu-Saifan, S. (2012). Social Entrepreneurship: Definition and Boundaries, Technology Innovation Management Review, 2(2), 22-27.

Alter, S. K. (2006). Social Enterprise Models and Their Mission and Money Relationships. In A. Nicholls (Ed.), Social entrepreneurship: New models of sustainable change, (pp. 205-232). New York, NY: Oxford University Press.

Austin, J., Stevenson, H. and Wei-Skillern, J. (2006). Social and Commercial Entrepreneurship: Same, Different, or Both? Entrepreneurship Theory and Practice, 30(1), 1-22. https://doi.org/10.1111/j.1540-6520.2006.00107.x

Beyhan, Ş. G, ve Ünügür, S. M. (2005). Çağdaş Gereksinmeler Bağlamında Sürdürülebilir Turizm ve Kimlik Modeli. İTÜDERGİII/a, 4(2).

Birleşmiş Milletler Çevre Programı ve Birleşmiş Milletler Dünya Turizm Örgütü (2005). Making Tourism More Sustainable - A Guide for Policy Makers, pp. 11-12.

Boukas, N. and Chourides, P. (2016). Niche Tourism in Cyprus: Conceptualizing the Importance of Social Entrepreneurship for the Sustainable Development of Islands. International Journal of Leisure and Tourism Marketing, 5(1), 26-43.

Bramwell, B. and Lane, B. (2002). The Journal of Sustainable Tourism: The First Ten Years, Journal of Sustainable Tourism, 10(1), 1-4.

Buckley, R. (2002). Surf Tourism and Sustainable Development in Indo-Pacific Islands. I. The Industry and the Islands. Journal of Sustainable Tourism, 10(5), 405-424.

Butler, R.W. (1999). Sustainable Tourism: A State-of-the Art Review. Tourism Geographies 1 (1), 725.

Çiftçi, F. ve Zencir E. (2019). Turizm Sektöründeki Sosyal Girişim Çalışanlarının Sosyal Girişimcilik Davranışı, İş ve Yaşam Tatmini: Tatuta Projesi Narköy Örneği, Turizm Akademik Dergisi, 6 (1), 131-145.

De Lange, D. and Dodds, R. (2017). Increasing Sustainable Tourism Through Social Entrepreneurship. International Journal of Contemporary Hospitality Management.29(7), 1977-2002.

Dees, J.G. (1998) The Meaning of Social Entrepreneurship, Available at: Stanford Business. Retrieved from http://csi.gsb.stanford.edu/sites/csi.gsb.stanford.edu/files/ themeaningofsocialentrepreneurship.pdf. (Erişim tarihi: 12 Şubat 2020).

Dees, J. G. (2001). The Meaning of Social Entrepreneurship. Newsletter of Duke Innovation and Entrepreneurship Initiative. Retrieved July 16, 2018, from https://entrepreneurship.duke.edu/news-item/the-meaning-of-socialentrepreneurship/

Duran, E. (2009). Sürdürülebilir Turizm Kapsamında Toplumsal ve Kültürel Kimliğin Korunması: Gökçeada Örneği (Doctoral dissertation, DEÜ Sosyal Bilimleri Enstitüsü). 
Dünya Turizm Örgütü (2000). Internet web-site (http:// www.world-tourism.org/) (Erişim tarihi: 12 Mart 2020).

Dünya Turizm Örgütü (2001). The Concept of Sustainable Tourism. On www at http://www.worldtourism. org/sustainable/concepts.htm. (Erişim tarihi: 9 Nisan 2020).

Flavin C., French H. and Gardner G. (2002). State of the World 2002. A World Watch Institute Report on Progress Toward a Sustainable Society. New York, London: W.W.Norton \& Company; p. 117.

Grassl, W. (2012). Business Models of Social Enterprise: A Design Approach to Hybridity, ACRN Journal of Entrepreneurship Perspectives, 1(1), 37-60.

Günlü, E. (2015). Sosyal Girişimcilik Olgusunun Kavramsal Analizi ve Turizmde Sosyal Girişimcilik. Mugla Sitki Kocman University Journal of Social Sciences, 35.

Hunter, C. (1997). Sustainable Tourism as an Adaptive Paradigm. Annals of Tourism Research, 24(4), 850-867.

Jackson, G., and Morpeth, N. (2000). Local Agenda 21. Reclaiming Community Ownership in Tourism or Stalled Process? In G. Richards \& D. Hall (Eds.), Tourism and Sustainable Community Development (pp. 119-134). London: Routledge.

Jacobs, M. (1991). The green economy. London: Pluto Press.

Kensbock, S. and Jennings, G. (2011). Pursuing: A Grounded Theory of Tourism Entrepreneurs' Understanding and Praxis of Sustainable Tourism", Asia Pacific Journal of Tourism Research, 16(5), 489-504.

Kerala Turizmi (2000). Tourism-Department of Tourism-Scheme for approval/classification of House Boats', Government of Kerala, (online), Thiruvananthapuram http://www.keralatourism.org/ Business/ Houseboat.htm.

Koenig, A. N. (2013). Social and Green Entrepreneurship Survey in Turkey: Methodology and findings. Retrieved from http://ipc.sabanciuniv.edu/en-old/wp-content/uploads/2012/10/131126Anja-Blog_Survey-methodology-and-results_final.pdf

Kokkranikal, J., and Morrison, A. (2002). Entrepreneurship and Sustainable Tourism: The Houseboats of Kerala. Tourism and Hospitality Research, 4(1), 7-20.

Kulakoğlu Dilek, N. ve Dilek, S. E. (2018). Turizm ve Sosyal Girişimcilik: Türkiye'den Gençtur Örneği, 1. Uluslararası GAP Sosyal Bilimler Kongresi, Şanlıurfa.

Laeis, G. C. and Lemke, S. (2016). Social Entrepreneurship in Tourism: Applying Sustainable Livelihoods Approaches. International Journal of Contemporary Hospitality Management. 28(6), 10761093.

Lane, B. (1991). Sustainable Tourism: A New Concept for the Interpreter. Interpretation, 8(29), 1-4.

Lane, B. (1994). Sustainable Rural Tourism Strategies: A Tool for Development and Conservation. Journal of Sustainable Tourism 2:102-1 11.

Lansing, P. and De Vries, P. (2007). Sustainable Tourism: Ethical Alternative or Marketing Ploy?, Journal of Business Ethics, 72(1), 77-85.

Lepoutre, J., Justo, R., Terjesen, S. and Bosma, N. (2013). Designing a Global Standardized Methodology for Measuring Social Entrepreneurship Activity: The Global Entrepreneurship Monitor Social Entrepreneurship Study. Small Business Economics, 40(3), 693-714. 
Liu, Z. (2003). Sustainable Tourism Development: A Critique. Journal of Sustainable Tourism, 11(6), $459-475$.

Lordkipanidze, M., Brezet, H. and Backman, M. (2005). The Entrepreneurship Factor in Sustainable Tourism Development. Journal of Cleaner Production, 13(8), 787-798.

Mair, J. And Marti, I. (2006). Social Entrepreneurship Research: A Source of Explanation, Prediction, and Delight. Journal of World Business, 41(1), 36-44.

McCool, S. F. and Lime, D.W. (2001). Tourism carrying capacity: tempting fantasy or useful reality?, Journal of Sustainable Tourism, 9(5), 372-388.

McDonald, J. R. (2006). Understanding Sustainable Tourism Development from a Complex Systems Perspective: A Case Study of The Swan River, Western Australia.

Middleton, V. T. C. and Hawkins, R. (1998). Sustainable Tourism: A Marketing Perspective. Oxford: Butterworth-Heinemann.

Page, S. J. and Dowling, R. K. (2002). Ecotourism. Harlow: Prentice Hall.

Peng, K. L. and Lin, P. M. (2016). Social Entrepreneurs: Innovating Rural Tourism Through the Activism of Service Science. International Journal of Contemporary Hospitality Management, 28(6), 1225-1244.

Petrin T. and Gannon A. (1997). Rural Development Through Entrepreneurship. REU Technical Series 41. Rome: FAO, Regional Office for Europe and Agriculture Organization of the United Nations.

Planeterra (2015). Community Tourism Development Learning Program, G Adventures, Planeterra Foundation, Inter-American Investment Bank, Toronto, available at: www.youtube.com/user/PlaneterraCares.

Pol, E. and Ville, S. (2009). Social Innovation: Buzz Word or Enduring Term? The Journal of SocioEconomics, 38(6), 878-885. https://doi.org/http://dx.doi.org/10.1016/j.socec.2009.02.011

Prieto, L. C., Phipps, S. T. A. and Friedrich, T.L. (2012). Social Entrepreneur Development: An Integration of Critical Pedagogy, The Theory of Planned Behavior and the ACS Model, Academy of Entrepreneurship Journal, 18(2), 1-15.

Rebutin, J. A. (2009). Social Enterprise and Tourism, The Key to a Better Integration of Indigenous Populations. Sociology. Université de Toulon et du Var. Erişim tarihi: 24.03.2020. http://dumas.ccsd.cnrs.fr/dumas00418823/file/Julia_Rebutin_Memoire_Social_Enterprise_and_I ndigeno us_Tourism.pdf

Ruhanen, L. (2013). Local Government: Facilitator or Inhibitor of Sustainable Tourism Development?. Journal of Sustainable Tourism, 21(1), 80-98.

Scharpf, H. (1998). Sürdürülebilirlik Açısından Bölgesel ve Yerel Yönetimlerin Turizm Politikasındaki Görevleri. 21. Yüzyılda Sürdürülebilir Turizm Politikaları, Editör, Semra Atabay, Uluslararası Turizm Sempozyumu, 16-17 Aralık.

Shaw, E. and Carter, S. (2007). Social Entrepreneurship: Theoretical Antecedents and Empirical Analysis of Entrepreneurial Processes and Outcomes. Journal of Small Business and Enterprise Development, 14(3), 418-434. https://doi.org/10.1108/14626000710773529.

Sheldon, P. J., Pollock, A. and Daniele, R. (2017). Social Entrepreneurship and Tourism: Setting the Stage. In P. J. Sheldon \& R. Daniele (Eds.), Social Entrepreneurship and Tourism, (pp. 1-18). Cham, Switzerland: Springer. doi: 10.1007/978-3-319-46518-0_1. 
Tetzschner, N. and Herlau, H. (2003). Innovation and Social Entrepreneurship in Tourism: A Potential for Local Business Development?, Working Papers 49/03, University of Southern Denmark, Esbjerg.

Tosun, C. (1998). Roots of Unsustainable Tourism Development at the Local Level: The Case of Urgup in Turkey. Tourism Management, 19(6), 595-610.

Volkmann, C. K., Tokarski, K. O. and Ernst, K. (Eds.). (2012). Social Entrepreneurship and Social Business: An Introduction and Discussion with Case Studies. Wiesbaden, Germany: Springer Gabler Verlag. doi: 10.1007/978-3-8349-7093-0.

Von der Weppen, J. and Cochrane, J. (2012). Social Enterprises in Tourism: An Exploratory Study of Operational Models and Success Factors. Journal of Sustainable Tourism, 20(3), 497-511. doi: 10.1080/09669582.2012.663377.

Weaver, D. and Lawton, L. (1999). Sustainable Tourism: A Critical Analysis. Gold Coast: CRC for Sustainable Tourism.

Zahra, S., Gedajlovic, E., Neubaum, D. O. and Shulman, J. M. (2009). A Typology of Social Entrepreneurs: Motives, Search Processes and Ethical Challenges. Journal of Business Venturing, 24(5), 519-532. https://doi.org/10.1016/j.jbusvent.2008.04.007.

Zeyen, A., Beckmann, M., Mueller, S., Dees, J. G., Khanin, D., Krueger, N., Murphy, P. J., Santos, F., Scarlata, M., Walske, J. And Zacharakis, A. (2013). Social Entrepreneurship and Broader Theories: Shedding New Light on the 'Bigger Picture'. Journal of Social Entrepreneurship, 4(1), 88107. 